\title{
The present situation and prospects for safety online-monitoring system of tailings pond
}

\author{
ZHOU Hanmin ${ }^{1, a}$, YUAN Ziqing ${ }^{1, b^{*}}$, SU Jun ${ }^{1}$, YANG Xiaocong ${ }^{1}$ and ZHANG \\ $\mathrm{Da}^{1}$
}

1 R \&D Center of Mining \& Metallurgy 507 room, Beixing road, Daxing district in Beijing city of China aahzhm2310@126.com, byanzitsing@126.com

\begin{abstract}
Keywords: Tailings pond; safety online-monitoring system; development direction; present situation; prospects

Abstract: Tailing pond is a major risk source, if happen accident, which would cause enormous losses to life and property of downstream people, however, the safety online-monitoring can effectively prevent the accident happing and reduce the accident loss. This article explains the present development and research situation of safety online-monitoring system for tailings pond, and also analyses shortages in subject-specific development, monitoring theory \& technology, management system and operations \& maintenance. At same time, according many experiences of safety online monitoring items, the article looks forward to the developing trend of safety online monitoring, and summarize the future development direction and the key point.
\end{abstract}

\section{Introduction}

Chinese is a mining country, according incomplete statistics, it has more than twelve thousand tailing ponds, and the most of which are dangerous or risky ponds [1] (Fig.1), Safety in production of tailing pond is very serious. Tailing pond is a major risk source, if happen accident, which would cause fatal disaster. There are many serious accidents in our country, that caused enormous losses to life and property of people and threatened the environmental security of around region, even influenced the social stability. For example: September in 1962, Huogushan tailing pond of Yunnan tin company limited had happened a dam break accident, which caused 171 peoples died, 92 peoples injured and 13970 peoples disaster, and also 8th September in 2008, tailing pond of Xinta mining company limited in Xiangfen county, Linfen city, Shanxi province had happened a big dam break accident, which caused 277 peoples died, 4 peoples lost, 33 peoples injured, enormous losses to life and property, and bad influence to society [2], therefore, it's necessary to effectively monitor the safety of tailing ponds. For preventing and reducing safety accidents of tailing ponds, government has published many documents to strengthen works of safety in production, and requires tailing ponds of the third class or above must install online monitoring system[3].Technical regulations for the tailings pond safety monitoring (AQ2030-2010) is published to regulate basic requirement for tailings pond safety monitoring form engineering angles. So far, mining enterprises in country have installed safety online monitoring system of tailings pond one after another, which greatly improve technology and efficiency of safety monitoring and management, and play a direction rote in safety monitoring \& early warning and management[4,5]. In the meantime, there are many shortages in subject-specific development, monitoring theory \& technology, management system and operations \& maintenance, for example, problems of limitations in monitoring methods, system building quality, integrated early warning mechanism and system operations \& maintenance etc, all of which seriously impact on normally playing a monitoring and early warming rote in online monitoring of tailings pond. It's necessary to research relevant solutions. This paper explains the present development and research condition of safety online-monitoring system for tailings pond, and also analyses shortages in development. At same time, according many experiences of safety online monitoring items, the article looks forward to the developing trend of safety online monitoring, and summarized the future development direction and the key point. 


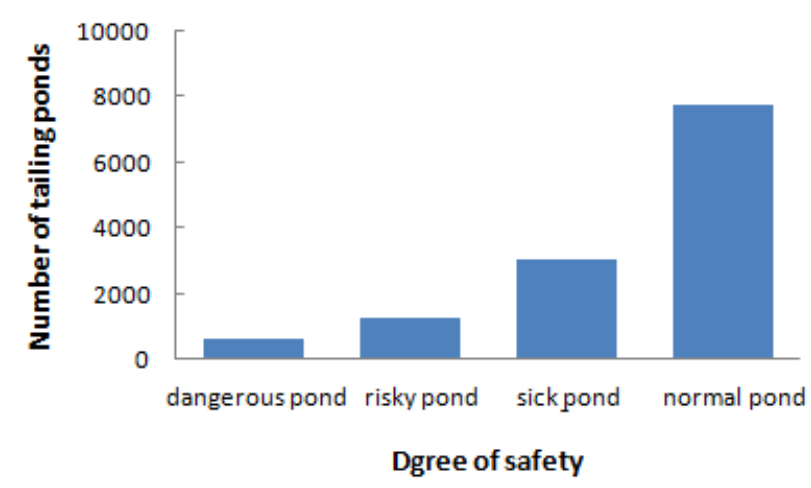

Fig.1 Safety distribution of tailings pond in China

\section{The present development condition}

Scholars in home have researched the key technology about safety online monitoring of tailings pond, the key research concentrate on system designing and developing, monitoring technology, data analysis and warming methods etc.

At the point of system designing and developing, YANG Xiaocong [6] designed a safety online monitoring system based a $\mathrm{B} / \mathrm{C}$ model of tailings pond, which used in many tailings ponds. ZHANG Feiyan [7]designed a wireless monitoring system to monitor tailings dam in GPRS and GSM technology. ZHANG Da [8] developed a three-dimensional safety warming platform based on researching key technology about online monitoring and safety warming.

Hu Jun [9] developed a tailings dam automatic monitoring system based on internet-intranet. LIAO Wenjing [10] build a three-dimensional safety monitoring and warming system concentrating on tailings pond remote monitoring, slope stability analysis, flood regulating \& checking and safety warming based on OpenGL and GIS. LEI Ting [11] constructed a wireless warming system based on wireless communication technology and concentrated on rainfall gauge, osmometer and data acquisition equipment. YI Dongfu [12] constructed a remote monitoring index system in systematic point and analytic hierarchy process. ZHOU Yipeng [13]developed a intelligent monitoring system solution based on Agent. ZHAO Jintong [14]designed a online monitoring system of tailings pond in light sensor.

At the point of monitoring technology, online monitoring concentrates on researching monitoring technology and method about tailings pond parameters and communicating \& defending technology. ZHU Yufeng[15]monitors operating condition and dam displacement of tailings pond in GPS and remote sensing image.ZHANG Jifeng[16]、HU Jun[17]monitor the beach length in image recognition method. YUAN Ziqing [18] advices a new method using in online monitoring for beach length - seepage inversion method, which arranges some osmometers in beach width to get the phreatic line, and then, by structuring the coordinate system of pond length to dam height, it calculates the beach width by calculating the equation set of phreatic line and water. SU Jun [19]monitors displacement and saturation line of tailings dam in fiber grating sensor.LI Daoming[20] automatic monitors dry beach index (elevation, length and slope) in laser measurement technology. WU Huanliang[21] monitors displacement of tailings dam in Beidou high-precision positioning. ZHAO Zhijun[22] brings the Zigbee wireless technology into safety monitoring of tailings dam. XU Tongle[23] advices a method transferring monitoring data in fiber and GPRS technology for ensuring the reliability of system transferring. OU Yangwei[24] probes into the lightning protection designing of tailings online monitoring system, and advices a new technology in biological bacterium resistance reduction, which can effectively reduce the grounding resistance.

At the point of data analysis and warming method, based on system of district warming index, XIE Xuyang [25] constructs a district warming model in method of Support Vector Machine. ZENG Qunwei [26] uses the saturation line and flood storage capacity as an index of tailings pond automatic monitoring. Utilizing comprehensive evaluation related theory of water reservoir dams and according to the implementation of tailings pond monitoring, HAN Zhilei[27] constructs a monitoring behavior 
comprehensive evaluation system of tailings pond, and also constructs a statistical regression model of saturation line in statistical regression theory, that analyses the influence of saturation line depth [28]. LIN Xuesong [29]calculates the warming value of saturation line, dry beach and safety factor by digital simulation method, and judges warming by contract the safety factor with regulation factor. CHEN Zhihua[30]constructs displacement forecasting mathematical model of tailings pond using the saturation line and water as external factors of displacement analysis. LI Lang[31] constructs mathematical model to forecast displacement of tailings dam in grey system theory based on monitoring data. XIE Zhenhua[32]constructs a RBF neural network model for analyzing the monitoring data.

Researching on tailings pond online monitoring system and technology, it finds that all online monitoring system accept the multilevel B/C construction of sensor + monitoring station + server (Fig. 2). Besides, no matter how about the actual situations, monitoring system almost has the same monitoring index, and the monitoring technology is single (Tab.1). At the same time, it can find that people increasingly pay attention to safety online monitoring of tailings pond, and more and more people gradually bring the modern advanced calculating, communicating, sensing and data analyzing technology into the safety online monitoring of tailings pond for achieving the scientization and intellectualization of tailings pond safety online monitoring.

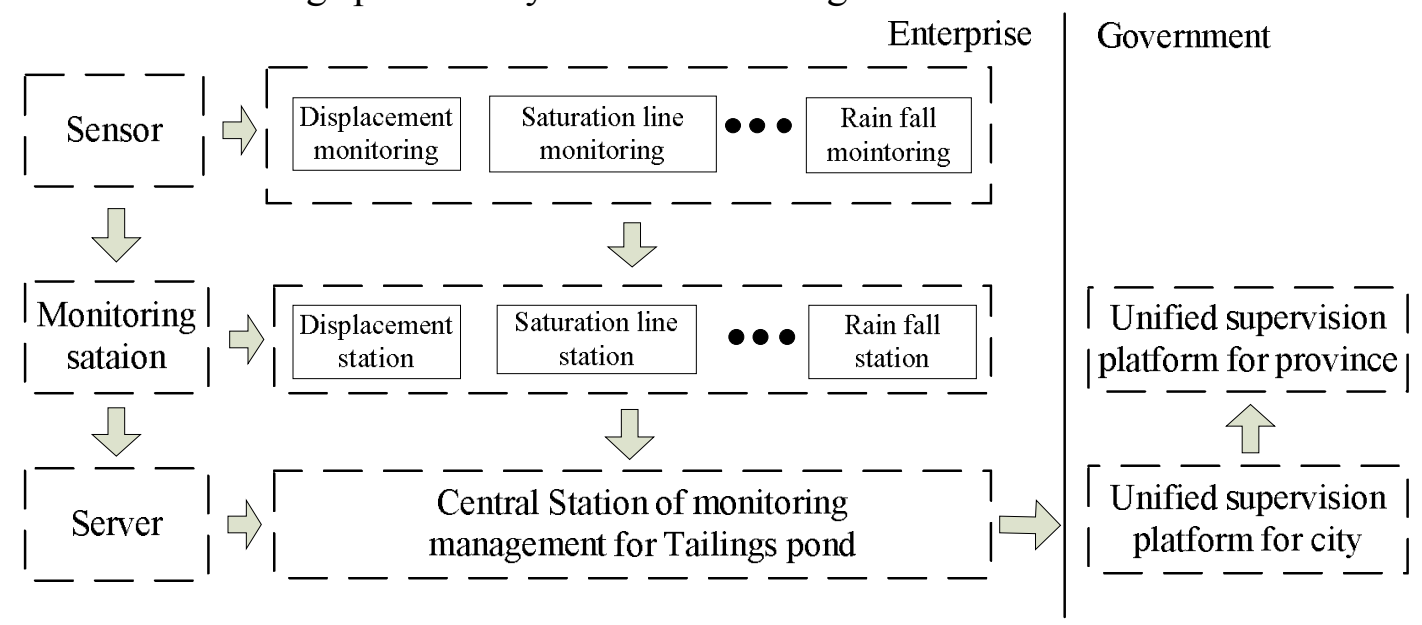

Fig.2 The frequent system construction of safety online-monitoring for tailings pond

Tab.1The frequent standards and technology or equipment table of safety online-monitoring for tailings pond

\begin{tabular}{|c|c|}
\hline Monitoring index & Monitoring technology or equipment \\
\hline Surface displacement & $\begin{array}{l}\text { GPS, intellectual total station, } \\
\text { hydrostatic leveling }\end{array}$ \\
\hline Internal displacement & $\begin{array}{l}\text { Fixed clinometers, } \\
\text { settlement meter }\end{array}$ \\
\hline Saturation line & Osmometer, water level gauge \\
\hline Dry beach length & $\begin{array}{c}\text { Camera, laser ranger, ultrasonic \& radar } \\
\text { levelmeter }\end{array}$ \\
\hline Beach crest height & $\begin{array}{c}\text { Laser ranger, ultrasonic } \& \text { radar } \\
\text { levelmeter }\end{array}$ \\
\hline Pool level & Osmometer, water level gauge \\
\hline Rain fall & $\begin{array}{l}\text { Tipping bucket and capacitance rain } \\
\text { gauge }\end{array}$ \\
\hline Seepage flow & Measuring weir, ultrasonic levelmeter \\
\hline Seepage pressure & Pore pressure gauge \\
\hline
\end{tabular}




\section{Deficiency of development of online monitoring}

From the above present situation of on line monitoring, we can see that there is a large number of on line monitoring systems about tailings pond and researchers have achieved good results in online monitoring related key technologies. But it still has the following disadvantages when looking at the current development of the whole tailings pond on line monitoring.

(1) Single existing monitoring techniques, low level of technological innovation and not enough data representation and accuracy. These phenomena are more obvious in displacement and invasive monitoring. The current dam displacement and invasive monitoring are almost point but not line and area monitoring. These monitoring has not enough representativeness to reflect the security status of tailings dam accurately and comprehensively. So it is quite necessary to develop large scale, large dimension and more representative new research about monitoring techniques and methods.

(2) The current tailings on line monitoring technology almost all use hydroelectric dam technology. Due to the differences in the engineering properties of the tailings dam, most data lack of accuracy. It is urgent to research and development new tailings dam engineering characteristics monitoring technology and sensors. For example, the method to monitor tailings moisture content in the bag and the inter story displacement of the mold bag tailings dams; How to monitor displacement of centre line method tailings dam et al.

(3) Fundamental theoretic research about the tailings pond on line monitoring system is not enough and lack of depth. The current on line monitoring technology has more applied research but software development, system integration degree and intelligence are still relatively lacking. Automatic safety comprehensive analysis and early warning function of the software is weak. Comprehensive warning method and early warning threshold value research about the tailings pond on line monitoring are very scarce. The current monitoring data in tailings rainfall, infiltration line and displacement can represent only one measuring point. It is difficult to solve the problem of comprehensive analysis in the whole tailings dam with multi parameter and measuring point data then timely evaluate the safety and early warning. In addition, due to the national norms and technical standards have not clearly define the monitoring indicators and its warning thresholds set, so the current setting of monitoring parameters early warning value lack of basis and guidance.

(4) There are no clear on line monitoring management system and construction standard in mining companies and the occupational specification[33]. So it can't guarantee the normalization of on line monitoring design, construction and acceptance. This situation directly impact the security of system construction and play of system security warning function.

(5) Mine enterprise lack of internal security needs of tailings pond on line monitoring, system operation and maintenance are inadequate, operational stability and continuity is time to be improved nor data integration and analysis deficiency. Tailings pond on line monitoring is mandatory under national administrative means to implement. So its system construction and internal demand for using are deficiency. Through investigations, many companies lack awareness of security risks. They still regard on line monitoring system as cope with administrative licensing examination and government departments and don't maintain the system effectively, the management system is also very imperfect. Although many scholars have done some analysis which were mostly simple and lack of timely data compilation and analysis, thus the state of tailings dam safety can't be accurate and timely evaluated[34]. These deficiencies made on line monitoring can't play roles on safety early warning and process guidance in the true sense.

(6) There is none national unity tailings pond on line monitoring platform, information sharing and integrated regulatory are inefficiency, regulatory platform overlap seriously which makes a waste of resources. Currently, each province independently regulates the construction and operation of tailings pond as well as on line monitoring system in their respective regions. So there is unbalanced regulatory standards, the standards are not uniform etc. are inevitable. These is not conducive to higher management and decision making. Also, because many provinces and cities have established a province innings different data interfaces tailings pond on line monitoring unified management platform. So the 
platforms are seriously overlapping, resulting in a great waste of resources and information sharing between platforms in lower level.

\section{Prospects for the online monitoring}

Nowadays, because of the guidance of the state policies and regulations, domestic mining enterprises safety consciousness increases ceaselessly and they also pay more attention to the safety management of the tailings dam. Along with the rapid development of computer, communication, electronic information as well as sensor technology, more and more safety monitoring technology, method and equipment is applied in the tailings dam safety online monitoring and management, thus online monitoring of tailings is equipped with more advanced hardware and its analysis and early warning is more timely and reliable. Meanwhile, it should not be neglected that the current online monitoring is lack of software, imbalance development and the fundamental research is not insufficient. Based on the cases of Shibahe tailing dam, Zhangdou tailing dam, Dapingzhang tailing dam, Laoyaling tailing dam, Jiashigou tailing dam, Xiaodae online monitoring tailing dam, The author think that the main direction and content of tailing dam online monitoring in the future should be as follows:

(1) Study on the new mode of tailings online monitoring and management system. Change the existed old mode "Sensor + Monitoring station + Server", applied advanced networking and cloud service technology, establish new mode of tailing dam safety online monitoring "Networking sensor + Cloud service + Terminal" (Figure 3). Study on the establishment of a national unified supervision of tailings online monitoring platform, and develop the corresponding software system, organization and management system.

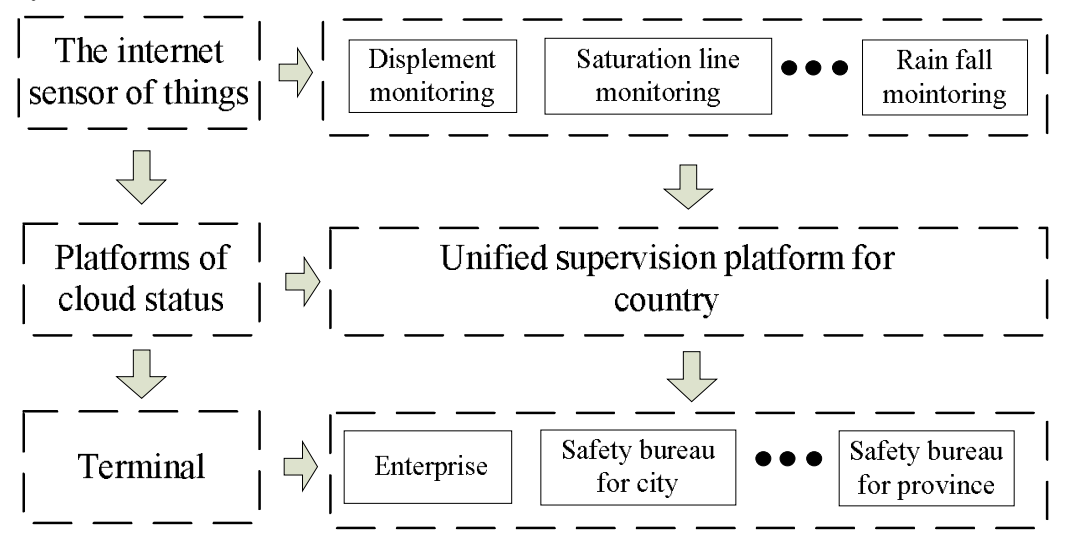

Fig. 3 Construction of online monitoring for tails pond based on "Internet of things + cloud status + terminal"

(2) Study on the tailing online monitoring theory and technology. Study on safety monitoring method and optimization of tailings, such as displacement and invasive method of optimal layout for line monitoring points. Study on method of early - warning indicators of online monitoring tailing; Study on comprehensive early - warning method and model of the multi parameter, multi measuring point, and developed the corresponding early warning system. Research on change regulation of each tailing monitoring indicators and establish the corresponding mathematical statistical analysis model. Online monitoring data processing method of tailings reservoir. Applied advanced electronic and sensing technology R \& D to tailings reservoir. Study on low cost, high reliability, high integration, intelligent online monitoring system. Research on large scale, multidimensional tailings dam internal hidden danger monitoring technology. Research on system protection technology research of ground tailings.

(3) Research on regulations and laws online monitoring of tailings. Formulate the code for design of online monitoring system of tailing reservoir, in order to clearly define the online monitoring system requirements and construction standards. Study on acceptance specifications of tailings pond on-line monitoring system construction; Clarify online monitoring system to ensure the quality of construction 
requirements, ensure the reliability of the system from the design stage, implementing stage to final acceptance of construction stage. Establish the corresponding operation rules for the tailings of online monitoring system.

\section{Conclusion}

The author reviewed the research and development status of domestic tailings online monitoring system, analysis the development of this subject, the monitoring theory, technology, management systems and the existing problems in operations. The conclusion can be drawn the as followings:

(1) In recent year, the tailings online monitoring has made great development and progress in system design and development, safety monitoring technology and methods. From the current research results, we can conclude that implementation of the advanced hardware technology and the methodology could be the inevitable trend of tailings dam safety online monitoring in China.

(2) Based on large amounts of analysis and several online monitoring cases, the author summarized the main direction of the future research on tailings safe online monitoring and revealed the research tendency of online monitoring field of tailings, which played a positive role in promoting China's tailings dam safety online monitoring research and development.

\section{References:}

[1]CHEN Xian. Research on reliable appraisal of the system of safety monitoring and warning of tailings [D]. Beijing, Capital University of Economics and Business, 2010:1. (in Chinese)

[2]YANGLi-hong, LIQuan-ming, CHENGWu-yi etc. The analysis of main risk factors about tailings dam accidents at home and abroad. [J]. China Safety Science Journal, 2008, 4(5): 28-31. (in Chinese )

[3]TIAN Wenqi. The suggestions of safety measure on current situation of tailing reservoir in China [A]. The Mining Academic Committee of The Nonferrous Metals)

[4] ZHANG Yong-ming. Application of automatic monitoring in tailings pond J. China Mine Engineering, 2010, 39 (6) : 11-14. (in Chinese)

[5] LI Zhongkui, LIAO Guoli. Design and research on monitoring and early warning system of tailings reservoir dam failure [J]. Nonferrous Metals: Mining Section, 2008, 60(6) : 33-35.(in Chinese)

[6] YANG Xiao-cong, YUAN Zi-qing, ZHOU Han-min etc. Application of safety online monitoring for tailing pond in the Tongkuangyu mine[J].Metal Mine, 2010 (Supp): 70-72. (in Chinese)

[7]ZHANG Feiyan. Study on the motoring system of tailings dam body stability in Lixi[M. S. Thesis][D].Wuhan: Wuhan University of Technology, 2004.(in Chinese)

[8]ZHANG Da, ZHANG Xiaopu, YANG Xiao-cong. Key technology and industrial application of on-line monitoring and emergency scheduling assistance system in tailing reservoir[J]. Mining and Metallurgy, 2011, 20(2): 20-25. (in Chinese)

[9] HU Jun. Automatic safety monitoring system of tailings dam based on internet-intranet[J]. Metal Mine, 2010, (2): 124-132.(in Chinese)

[10] LIAO Wen-jing, HUANG FU Kai-long, HE Yi etc. Integrated real-time monitoring, analyzing and analyzing pre-warning system for tailings reservoir[J]. China Safety Science Journal,2014, 24(8): 159-162. (in Chinese)

[11] Lei Ting, Tan Zhuoying.School Civil and Enviromnental Engineering System of Tailing Pond bases on Wireless Sensor Networks[J]. METAL MINE，2014, 451(1):125-127. (in Chinese ) 
[12] YI Dongfu DENG Hongwei ZHANG Rui. Construction of Remote Monitoring Index System for Tailings Reservoirs Based on Analytic Hierarchy process [J].Industrial Safety and environmental Protection, 2012,38(4):85-89. (in Chinese)

[13] Zhou Yipeng, Hu Juan. Intelligent Tailings Pond Monitoring System Based on Agent[J]. Metal Mine, 2012,435 (9):107-110. (in Chinese)

[14] ZHAO Jin-tong, ZHAO Chang-zhong. DESIGN OF TAILINGS LINE MONITORING SYSTEM IN LUCHANGGOU MINE [J]. CHINA MOLYBDENUM INDUSTRY,2011,35(4): 26-29. (in Chinese)

[15] Zhu Yufeng, Lu Tieding, Zhou Shijian etc.Discussion on Monitoring of Uranium Tailing Pond Based on GPS Combined with Remote Sensing Images[J]. METAL MINE,2012, 432 (6) : 92-94.

(in Chinese)

[16] Zhang Jifeng, Li Shaobo. Application of Close-range Photogrammetry in Dry Beach of Tailings Pond Monitoring[J]. Modern Mining,2014,542(6):54-57. (in Chinese)

[17] HU Jun,LIU Zebei, HU Shan. Tailings Bry Beach Length Monitoring Based on the Visual Measurement[J]. Industrial Safety and Environmental Protection, 2014,40(11):1-4. (in Chinese)

[18] YUAN Zi-qing, YANG Xiao-cong, ZHANG Da etc. A new method for online monitoring on beach width of tailings pond [J]. Journal of Safety Science and Technology,2014,10（7）:71-75. (in Chinese)

[19] SU Jun, WANG Zhi-yu, YUAN Zi-qing etc. A new method for online monitoring on beach width of tailings pond [J]. Journal of Safety Science and Technology,2014,10 (7):65-70. (in Chinese)

[20] Li Daoming Yu Guoping Shen Louyan etc. Application and Research on Automatic Monitoring and Early Warning System of Tailings Dry Beach[J].MODERN MINING, 2014, 540 (4) : 42-44.

(in Chinese)

[21] Wu Huanlang. Tailings Online Monitoring Based on High Precision Beidou Positioning[J].

Microcontrollers \& Embedded Systems, 2014,2:77-79. (in Chinese)

[22]ZHAO Zhijun, YAN Gaowei, XIE Keming. Research on safety monitoring system of tailing dams[J].Modern Electronic Technique, 2010, (5): 197-199.(in Chinese)

[23] XU Tongle, LANG Xuezheng, PEI Xincai, et al. Research on safety monitoring and early-warning system of tailing reservoir based on optical fiber transmission[J]. Gold, 2011, 32(7): 43-47.(in Chinese))

[24]OUYANG Wei,XU Weihuan. Lightning Protection Grounding Design of Tailings Safety Monitoring Device[J]. Nonferrous Metals Engineering \& Research , 2014, 35(4):15-17. (in Chinese)

[25] XIE Xuyang, JIANG Tianhan, WANG Yunhai etc. The study on regional alert of tailing reservoir based on support vector machine[J]. Journal of Safety Science and Technology, 2008, 4(4): 17-21.(in Chinese)

[26] ZENG Qunwei, XIE Dianrong, Su Juduan etc. Risk analysis of dam failing of the tailings reservoir[J].Industrial Safety and Environmental Protection, 2010, 36(1): 44-46.(in Chinese))

[27] HAN Zhi-lei, SU Jun, YANG Xiao-cong. Comprehensive evaluation method study on monitoring behavior of tailings pond[J]. China Mining Magazine, 2014, 23:199-202. (in Chinese) 
[28] HAN Zhi-lei, GUO Li-jie, YANG Xiao-cong. Regression analysis of saturation line online monitoring for tails pond[J].MODERN MINING, 2012，517（5）:73-76.（in Chinese）

[29] LIN Xuesong, CHEN Dianqiang, HE Feng. Calculation of monitoring warning value of tailing dam s seepage line and dry beach [J]. Journal of Water Resources and Water Engineering, 2014, 25(4): 66-68. (in Chinese)

[30] CHEN Zhi-hua1, SHI Kun, SHI Hua-lin. Analysis on Tailings Dam Deformation Monitoring based on Hydrological Factors [J].Surveying and Mapping of Geology and Mineral Resources, 2014, 30( 1$): 35-37$. (in Chinese)

[31] LI Gang. Research on the displacement forecasting methods of tailings dam deformation based on the gray system theory[J]. Journal of Safety Science and Technology, 2012, 8(4): 107-110.(in Chinese))

[32] Xie Zhenhua, Chen Qing. RBF Neural Network Method for Analyzing Monitoring Data of Tailings Dam[J]. METAL M INE, 2006, 364 (10): 69-70. (in Chinese)

[33] YUAN Zi-qing, YANG Xiao-cong etc. Study On Normalized Constructing Of Online Monitoring System For Tailings Pond[J]. MODERN MINING, 2014, 541（5）:127-128. (in Chinese )

[34] YU G M, SONG C W. Applications of online monitoring technology for tailings dam of digital mine [J]. Transactions of Nonferrous Metals Society of China, 2011, 21( 3): 604-609. 